\title{
Effects and safety of daily ingestion of plum extract on blood pressure: randomized, double-blinded, placebo-controlled parallel group comparison study
}

\author{
Mie Nishimura $^{1}$, Hiroyuki Kume ${ }^{2}$, Akio Kadowaki ${ }^{2}$, Nobuki Gato ${ }^{2}$, and Jun Nishihira ${ }^{1}$
}

${ }^{1}$ Department of Medical Management and Informatics, Hokkaido Information University, Ebetsu, Hokkaido, 069-8585, Japan; ${ }^{2}$ NAKANO BC Co. Ltd., Kainan, Wakayama, 642-0034, Japan

Corresponding author: Jun Nishihira, MD, PhD, Department of Medical Management and Informatics, Hokkaido Information University, Nishi Nopporo 59-2, Ebetsu 069-8585 Hokkaido, Japan

Submission Date: September $20^{\text {th }}$, 2017; Acceptance Date: November $28^{\text {th }} ; 2017$, Publication Date: November $30^{\text {th }}, 2017$

Citation: Nishimura M., Kume H., Kadowaki A., Gato N., Nishihira J., Effects and Safety of Daily Ingestion of Plum Extract on Blood Pressure: Randomized, Double-Blinded, Placebo-Controlled Parallel Group Comparison Study. Functional Foods in Health and Disease 2017; 7(11): 873-888. https://doi.org/10.31989/ffhd.v7i11.394

\begin{abstract}
Background: Hypertension is an increasing health issue in Japan. Plums are widely consumed in Japan and are reported to have various health benefits, including improvements to blood flow. However, clinical trials investigating the effects of plum extract on blood pressure have not yet been conducted. Therefore, we evaluated the effects and safety of plum extract on blood pressure in this randomized, double-blinded, and placebo-controlled parallel group comparison study.
\end{abstract}

Methods: Seventy-four healthy Japanese subjects with systolic blood pressure (SBP) $\geq 130$ and $<160 \mathrm{mmHg}$ were randomly divided into test and placebo groups. Subjects were given either plum extract-processed food (3.0 g of plum extract, containing $30 \mathrm{mg}$ of mumefural and $1.119 \mathrm{~g}$ of citric acid) or placebo food daily for 12 weeks. Physical examinations, blood measurements, and medical interviews were performed at weeks $0,4,8$, and 12 and at 2 weeks after the intake period. 
Results: SBP and diastolic blood pressure (DBP) did not significantly differ between the groups. However, in subjects with grade I hypertension, DBP was significantly lower in the active test food group than in the placebo food group at week 12 and at 2 weeks after the intake period. An exploratory subgroup analysis revealed that plum extract improved DBP in subjects with normal to high obesity/class I obesity at week 12. Moreover, plum extract had positive effects on fatigue and bowel movements as determined by visual analog scale questionnaire evaluation. No abnormal changes or severe adverse events were observed in the physical examinations, blood measurements, or medical interviews in this trial.

Conclusion: These results suggest that plum extract is safe for long-term intake and improves DBP in subjects with grade I hypertension.

Keywords: blood pressure, clinical trial, mild hypertension, plum extract

\section{Clinical trial registration: UMIN000023184}

\section{BACKGROUND:}

It is estimated that there are 43 million people with treated or untreated hypertension in Japan [1]. In recent years, hypertension has increasingly been shown to be accompanied by lifestyle diseases such as obesity, dyslipidemia, and diabetes [2-3]. Research has shown that hypertension is related to the cause of cerebrovascular disease, cardiovascular disease, and dementia [4-5]. The prevalence of hypertension increases with age; accordingly, there is concern that the number of patients with hypertension will increase with Japan's aging society [6]. Although various antihypertensive drugs with different mechanisms have been developed, multiple drug combinations are used in current standard therapy. Therefore, lifestyle improvement, such as diet modification, has become extremely important in addition to medical therapy; various functional foods for prevention of hypertension were also researched [7-8].

Plums (Prunus mume Sieb. et Zucc) have been consumed for centuries in Japan and processed into various foods, such as "Umeboshi," plum wine or plum extract [9]. Approximately 200 varieties are cultivated as edible fruits, and the fruit has been used in folk medicine to alleviate fever, cough, and intestinal disorders [10] and has been consumed for many years in Wakayama, Japan. It is believed to have antibacterial effects and cure typhus fever, diarrhea caused by dysentery/diarrhea, and food poisoning [9]. Moreover, recent research has suggested that plum extract has various other effects, such as antigastric ulcer, antioxidant effects, and antivascular 
hypertrophy [9]. Plum extract is produced by concentrating plum to a moisture content of around $20 \%$. It contains a high amount of citric acid [10], an $\alpha$-hydroxy acid abundant in citrus fruits. It plays a central role in energy metabolism and has antifatigue effects [11]. Citric acid has also shown to promote antiplatelet aggregation [12] and has antiblood coagulation effects [13].

Mumefural (1-[5-(2-formylfuryl)methyl] dihydrogen 2-hydroxypropane-1,2,3-tricarboxylate) was identified in plum extract as a functional component and is produced by heating sugar and the citric acid contained in unripe plums [14]. It was revealed that mumefural promotes erythrocyte deformability, inhibits platelet aggregation, and improves blood flow [9]. Previous research identified mumefural and its analogs in plum extract and intake of plum extract improved blood flow in healthy subjects [14]. Furthermore, mumefural was gradually degraded to citric acid and 5-hydroxymethyl-2-furfural in blood. Therefore, mumefural may contribute to sustaining the concentration of citric acid. These findings suggest that improved blood flow by plum extract was not only due to citric acid but also mumefural. However, clinical trials investigating the effects of plum extract on blood pressure have not yet been conducted.

We assessed the efficacy of plum extract on blood pressure in 80 healthy subjects (aged 3069 years) with hospital systolic blood pressure (SBP) $\geq 130$ and $<160 \mathrm{mmHg}$ in a 12-week randomized, double-blinded, placebo-controlled parallel group comparison study.

\section{METHODS:}

\section{Study Subjects}

We recruited 161 volunteers with mild elevated blood pressure. All volunteers provided written informed consent to participate in this clinical study. Finally, through screening tests, we selected 80 healthy Japanese subjects (aged 30-69 years). These included individuals with an SBP $\geq 130$ and $<160 \mathrm{mmHg}$ and who were judged by a physician as not needing hospital treatment for hypertension. Inclusion and exclusion criteria is shown in Table 1.

The 80 eligible subjects were randomly assigned to active test food or placebo food groups, with adjustments for sex, age, and level of SBP. A randomization sequence was created using a permuted block randomization design stratified by sex, age, and level of SBP. To ensure a balanced design, each subject was assigned to a relevant group by a third-party data center according to the randomization. The third-party data center concealed the assignment information, including the subjects' personal data, keeping it secure for the duration of the trial so that all staff (doctors, nurses, clinical research coordinators, and statistical analyzers) had no knowledge of the participating subjects. This information was only disclosed after the laboratory and analysis data were fixed, and the method of statistical analysis was finalized. 
Table 1. Inclusion and exclusion criteria

\begin{tabular}{ll}
\hline Inclusion & 1. SBP $\geq 130$ and $<160 \mathrm{mmHg}$ \\
criteria & 2. Judged by a physician as not needing hospital treatment for hypertension \\
\hline & 1. Receiving medication for hypertension \\
& 2. Serious cerebrovascular, cardiac, hepatic, renal, or gastrointestinal disease \\
& 3. Had a major surgical history related to the digestive system \\
4. Unusually abnormal hematological data or serious anemia & 5. Regularly taking medicine, functional foods, and/or supplements that would \\
criteria & improve hypertension \\
& 6. Heavy smokers, alcohol addicts, or subjects with an irregular lifestyle \\
& 7. A severe allergic reaction to foods, particularly plum, fruits of the family \\
& Rosacea, and/or white birch pollen \\
& 8. Other medical reasons, as judged by the principal investigator
\end{tabular}

\section{Study Design}

The clinical study was conducted as a randomized, double-blinded, placebo-controlled parallel group comparison study and was carried out in the Hokkaido Information University, Health Information Science Research Center (Ebetsu city, Hokkaido, Japan). The examination schedule for this study is shown in Table 2. We performed vital signs measurements and visual analog scale (VAS) questionnaires at weeks 0 (baseline), 4, 8, and 12 after the start of test food ingestion and 2 weeks after the end of test food ingestion (week 14). At each time point, a medical interview was conducted by a physician. Physical, hematological, and biological examinations were performed at weeks $0,4,8$, and 12 . We asked the subject groups to consume $10 \mathrm{~g}$ of test food three times a day (total $30.0 \mathrm{~g} /$ day) before each meal, with either active test food containing $1.0 \mathrm{~g}$ of plum extract (total $3.0 \mathrm{~g} /$ day) or placebo food. The volume of plum extract was determined using primary clinical trial. During this study, subjects were asked to not change their daily activities, including food consumption, medication, and exercise, and keep a life diary during the study period. The primary outcome was hospital blood pressure, and the secondary outcome was the VAS questionnaire score. 
Table 2. Examination schedule

\begin{tabular}{|c|c|c|c|c|c|c|c|c|}
\hline & \multirow[b]{2}{*}{$\begin{array}{l}\text { Guidance } \\
\text { and } \\
\text { agreement }\end{array}$} & \multirow[b]{2}{*}{ Screening } & \multirow[b]{2}{*}{ Randomization } & \multicolumn{4}{|c|}{ Test food intake period } & \multirow[b]{2}{*}{$\begin{array}{c}\text { Week } \\
14\end{array}$} \\
\hline & & & & $\begin{array}{c}\text { Week } \\
0\end{array}$ & $\begin{array}{c}\text { Week } \\
4\end{array}$ & $\begin{array}{c}\text { Week } \\
8\end{array}$ & $\begin{array}{c}\text { Week } \\
12\end{array}$ & \\
\hline Date & $\begin{array}{l}\text { Jul 20- } \\
23,2016\end{array}$ & $\begin{array}{l}\text { Jul } 20- \\
23,2016\end{array}$ & Aug 1, 2016 & $\begin{array}{c}\text { Sep } 1 \\
-3\end{array}$ & $\begin{array}{l}\text { Sep } \\
29- \\
\text { Oct } 1\end{array}$ & $\begin{array}{c}\text { Oct } \\
27- \\
29\end{array}$ & $\begin{array}{c}\text { Nov } \\
24- \\
26\end{array}$ & $\begin{array}{l}\text { Dec } 8 \\
-10\end{array}$ \\
\hline $\begin{array}{l}\text { Medical } \\
\text { interview }\end{array}$ & - & o & - & 0 & 0 & 0 & 0 & 0 \\
\hline $\begin{array}{l}\text { Vital signs } \\
\text { measurement }\end{array}$ & - & O & - & ○ & O & o & 0 & 0 \\
\hline $\begin{array}{l}\text { Physical } \\
\text { measurement }\end{array}$ & - & O & - & 0 & 0 & 0 & 0 & - \\
\hline $\begin{array}{l}\text { Blood } \\
\text { sampling }\end{array}$ & - & O & - & O & 0 & 0 & 0 & - \\
\hline $\begin{array}{l}\text { VAS } \\
\text { questionnaire }\end{array}$ & - & - & - & ० & ० & ○ & ○ & o \\
\hline Diary record & - & - & - & & & & & \\
\hline
\end{tabular}

\section{Preparation of Test Food}

The plum used in the active test food in this trial was cultivated in Wakayama, Japan. The manufacturing process for active test food containing $3.0 \mathrm{~g}$ plum extract was the following: materials (plum extract, erythritol, xanthan gum, fragrance, and sweetener) were mixed, followed by hot filling at $90^{\circ} \mathrm{C}$. The manufacturing process for the placebo food was the same except for the materials used (caramel, erythritol, L-tartaric acid, xanthan gum, fragrance, and sweetener). Analytical results of the nutrient composition for active test food and placebo food used in this study are provided in Table 3. Analysis of the nutrient composition was performed by the Japan Food Research Laboratories (Chitose, Japan). Citric acid was measured using high-performance liquid chromatography (HPLC) at the Japan Food Research Laboratories. Mumefural was measured using HPLC at NAKANO BC, Co Ltd. The active test food and placebo food were identical in appearance. The test foods were manufactured under strict quality control at the NAKANO BC Co. Ltd. with ISO9001 certification. 
Table 3. Nutrient composition of test foods (per $30 \mathrm{~g}$ )

\begin{tabular}{lcc} 
& Placebo food & Active test food \\
\cline { 2 - 3 } Calories (kcal) & 14.4 & 15.3 \\
Water (g) & 26.31 & 25.71 \\
Proteins (g) & - & 0.12 \\
Lipids (g) & - & - \\
Carbohydrates (g) & 3.63 & 4.02 \\
Ash (g) & 0.06 & 0.15 \\
Sodium (mg) & 37.5 & 7.32 \\
Mumefural (mg) & - & 30 \\
Citric acid (g) & 0.021 & 1.119 \\
\hline
\end{tabular}

\section{Hospital Blood Pressure Measurements}

Blood pressure (BP) was measured by a doctor or nurse using an Automatic Blood Pressure Monitor HEM-7080IC (Omron Colin Co., Ltd., Tokyo, Japan) using the upper arm on the nondominant arm after $>10$-min rest. Three sequential measurements were performed, and the median of the measurements was taken at each evaluation point.

\section{VAS Questionnaire}

To evaluate the effects of plum extract on fatigue, chillness, and bowel movements, the subjects completed a VAS questionnaire consisting of eight questions assessing (1) fatigue, (2) stiffness of the neck and shoulders, (3) stiffness of the waist, (4) chillness in hands and feet, (5) defecation regularity, (6) defecation difficulty, (7) defecation satisfaction, and (8) fecal odor. Subjects were instructed to mark a "cross" on a 100-mm line to answer each question based on their current health condition. The left end of the line $(0 \mathrm{~mm})$ was defined as the worst condition and the right end (100 $\mathrm{mm})$ as the best condition. The questionnaire results were assessed by evaluating the length from the start of the line on the left to the cross. An increase in VAS score indicated an improvement for each symptom.

\section{Physical, Hematological, and Biological Measurements}

Blood was collected after a 12-h fast. General blood tests were performed, including measurement of complete blood counts (CBCs; WBCs, RBCs, $\mathrm{Hb}, \mathrm{Ht}$, and Plt), liver function (AST, ALT, $\gamma$-GTP, ALP, and LDH), kidney function (BUN, CRE, and UA). Blood tests were performed by the Sapporo Clinical Laboratory, Inc. (Sapporo, Japan). Each subject's body composition was measured using a Body Composition Analyzer DC-320 (Tanita Corp, Tokyo, Japan).

\section{Ethics Committee}

All subjects provided written informed consent prior to undergoing any of the tests related to this study. The Ethics Committee of Hokkaido Information University approved the study protocol conforming to the Helsinki Declaration and Ethical Guidelines for Medical and Health Research Involving Human Subjects (approval date, Jul 21, 2016; approval number 2016-02). This study was registered with UMIN Clinical Trials Registry (approval number UMIN000023184). 


\section{Sample Size}

The sample size was statistically determined to obtain a power of $80 \%$ with an alpha of 0.05 . To demonstrate SBP at week 12, which was postulated to have an intergroup difference of $7 \mathrm{mmHg}$ with a standard deviation (SD) of $10 \mathrm{mmHg}$, a sample size of 72 (36 in each group) was required. Assuming a $10 \%$ loss in the follow-up rate, 80 subjects were selected.

\section{Statistical Analysis}

Values are presented in the tables as means \pm SD. Changes in subject values were analyzed using repeated measures ANOVA between the groups for evaluation of BP. Moreover, changes in subject values were analyzed using Student's $t$ test for evaluations of physical, hematological, and biological parameters between active test food and placebo food at each evaluation point. $p$ value $<0.05$ was considered to be significant. Statistical analyses were performed using SPSS Statistics 19 (IBM, Armonk, NY, USA).

\section{RESULTS}

\section{Subject Dropouts, Exclusions, and Characteristics}

During the trial, five subjects withdrew (started treatment, $n=3$; irregular lifestyle, $n=1$; personal reasons, $n=1$ ). Consequently, 75 subjects completed this trial (placebo food group, $n=38$; active test food group, $n=37$ ). One subject was excluded from the analysis of the "per-protocol set" because of an irregular lifestyle (placebo food group, $n=1$ ). We included 74 subjects in the PPS analysis for efficacy analysis (placebo food group, $n=37$; active test food group, $n=37$ ), and 80 subjects in ITT analysis for safety analysis (placebo food group, $n=40$; active test food group, $n$ $=40$ ). The study flow diagram is shown in Fig. 1 .

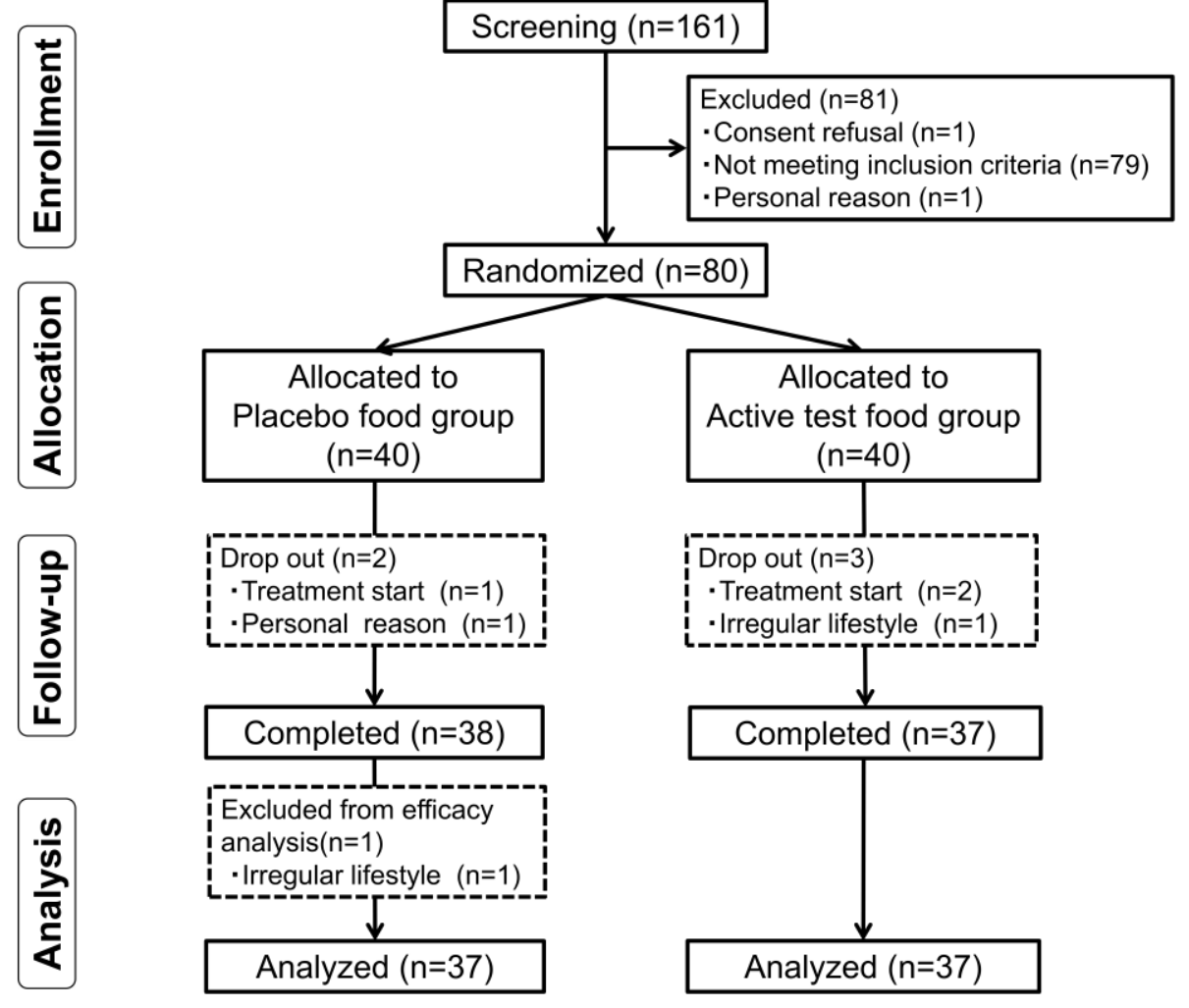

Figure 1. Flow diagram of the trial. 
The mean age, height, body weight, body mass index, SBP, and DBP for each group are presented in Table 4. These data did not differ significantly between the active test food and placebo food groups, confirming the appropriate allocation of subjects into the two groups. Moreover, there were no differences between the active test food and placebo food groups regarding intake rate (Table 4).

Table 4. Characteristics of the subjects in the active test food and placebo groups

\begin{tabular}{llll}
\hline Characteristic & Placebo & Active & $\boldsymbol{p}$ \\
\hline Subjects, $n$ & 37 & 37 & - \\
Male, $n$ & 10 & 12 & 0.80 \\
Age, years & $57.78 \pm 8.78$ & $57.49 \pm 9.21$ & 0.89 \\
Height, cm & $157.34 \pm 7.02$ & $160.56 \pm 8.58$ & 0.08 \\
Body weight, kg & $55.91 \pm 11.03$ & $58.12 \pm 8.66$ & 0.34 \\
Body mass index, kg/m ${ }^{2}$ & $22.44 \pm 3.17$ & $22.49 \pm 2.36$ & 0.95 \\
Systolic blood pressure, & $139.11 \pm 11.03$ & $141.03 \pm 12.40$ & 0.48 \\
mmHg & & & \\
Diastolic blood pressure, & $81.51 \pm 9.05$ & $84.41 \pm 8.79$ & 0.17 \\
mmHg & & & 0.26 \\
Intake rate, \% & $98.39 \pm 3.01$ & $99.04 \pm 1.61$ & \\
\hline
\end{tabular}

Values are shown as the mean \pm standard deviation. Analyses were performed using Student's $t$ test for age, height, body weight, body mass index, systolic blood pressure, and diastolic blood pressure, and chi-square test was used for gender. Mann-Whitney's $U$ test was used to analyze the intake rate. $n$, number of subjects.

\section{Effects of Plum Extract on Blood Pressure}

We evaluated the effects of plum extract on BP (Table 5). There were no differences between the active test food and placebo food groups regarding changes in SBP and DBP. However, in subjects with grade I hypertension (SBP $\geq 140$ and $<169 \mathrm{mmHg}$ or DBP $\geq 90$ and $<100 \mathrm{mmHg}$ ), DBP was significantly lower in the active test food group than the placebo food group at weeks 12 and 14 (change from baseline to week 12: placebo, $4.21 \pm 4.92 \mathrm{mmHg}$; active, $-1.53 \pm 7.28 \mathrm{mmHg}, p=$ 0.019 and change from baseline to week 14: placebo, $3.86 \pm 4.07 \mathrm{mmHg}$; active, $-2.80 \pm 7.08$ $\mathrm{mmHg}, p=0.005)$. In an exploratory subgroup analysis, DBP significantly decreased at week 12 (change from baseline to week 12: placebo, $4.50 \pm 7.68 \mathrm{mmHg}$; active, $-1.64 \pm 7.28 \mathrm{mmHg}, p=$ 0.047 ) and the time-group interaction of change value of DBP was significant $(p=0.009)$ following ingestion of the active test food in subjects with normal to high obesity or class I obesity. Moreover, SBP tended to decrease at week 12 (change from baseline to week 12: placebo, $3.58 \pm$ $12.84 \mathrm{mmHg}$; active, $-4.36 \pm 13.70 \mathrm{mmHg}, p=0.14$ ) and the time-group interaction of change value of SBP was significant in the same subject group $(p=0.008)$. 
Table 5. Measurement of blood pressure

\begin{tabular}{|c|c|c|c|c|c|c|c|}
\hline & & Week 0 & $\triangle$ week 4 & $\triangle$ week 8 & $\triangle$ week 12 & $\triangle$ week 14 & $p^{\mathbf{b}}$ \\
\hline \multirow{3}{*}{$\begin{array}{l}\mathrm{SBP} \text { in all subjects } \\
(\mathrm{mmHg})\end{array}$} & Placebo & $132.16 \pm 10.60$ & $1.24 \pm 10.59$ & $2.41 \pm 9.69$ & $-0.22 \pm 11.41$ & $-1.92 \pm 11.86$ & \multirow{3}{*}{0.59} \\
\hline & Active & $132.81 \pm 12.34$ & $3.68 \pm 10.88$ & $1.97 \pm 13.87$ & $1.62 \pm 12.84$ & $-2.19 \pm 12.03$ & \\
\hline & $p^{a}$ & 0.81 & 0.33 & 0.88 & 0.52 & 0.92 & \\
\hline \multirow{3}{*}{$\begin{array}{l}\text { DBP in all subjects } \\
(\mathrm{mmHg})\end{array}$} & Placebo & $81.03 \pm 8.14$ & $1.73 \pm 5.72$ & $2.32 \pm 4.88$ & $2.03 \pm 5.71$ & $0.43 \pm 5.62$ & \multirow{3}{*}{0.91} \\
\hline & Active & $81.92 \pm 7.91$ & $1.19 \pm 5.98$ & $1.17 \pm 7.55$ & $0.81 \pm 7.21$ & $-0.51 \pm 7.45$ & \\
\hline & $p^{a}$ & 0.63 & 0.69 & 0.44 & 0.43 & 0.54 & \\
\hline \multirow{3}{*}{$\begin{array}{l}\text { SBP in subjects with } \\
\text { high-normal blood } \\
\text { pressure (mmHg) }\end{array}$} & Placebo & $128.30 \pm 9.56$ & $0.70 \pm 12.00$ & $3.55 \pm 9.54$ & $-0.47 \pm 11.25$ & $-1.60 \pm 12.60$ & \multirow{3}{*}{0.67} \\
\hline & Active & $128.21 \pm 11.89$ & $3.26 \pm 11.49$ & $3.56 \pm 13.10$ & $2.53 \pm 13.06$ & $-0.11 \pm 11.51$ & \\
\hline & $p^{a}$ & 0.98 & 0.50 & 1.00 & 0.45 & 0.70 & \\
\hline \multirow{3}{*}{$\begin{array}{l}\text { DBP in subjects } \\
\text { high-normal bl } \\
\text { pressure (mmHg) }\end{array}$} & Placebo & $80.35 \pm 7.87$ & $0.90 \pm 5.68$ & $1.95 \pm 5.31$ & $1.21 \pm 5.57$ & $-1.20 \pm 5.60$ & \multirow{3}{*}{0.25} \\
\hline & Active & $80.05 \pm 7.42$ & $1.63 \pm 5.69$ & $2.06 \pm 6.47$ & $2.26 \pm 7.36$ & $1.47 \pm 7.93$ & \\
\hline & $p^{a}$ & 0.90 & 0.69 & 0.96 & 0.62 & 0.23 & \\
\hline \multirow{3}{*}{$\begin{array}{l}\text { SBP in subjects with } \\
\text { grade I hypertension } \\
(\mathrm{mmHg})\end{array}$} & Placebo & $134.93 \pm 10.20$ & $2.29 \pm 7.62$ & $2.14 \pm 10.47$ & $0.50 \pm 12.94$ & $-1.29 \pm 11.93$ & \multirow{3}{*}{0.57} \\
\hline & Active & $136.33 \pm 11.71$ & $3.00 \pm 11.04$ & $-1.60 \pm 15.44$ & $-0.07 \pm 14.09$ & $-5.07 \pm 12.44$ & \\
\hline & $p^{a}$ & 0.73 & 0.84 & 0.46 & 0.91 & 0.41 & \\
\hline \multirow{3}{*}{$\begin{array}{l}\text { DBP in subjects with } \\
\text { grade I hypertension } \\
(\mathrm{mmHg})\end{array}$} & Placebo & $80.07 \pm 8.29$ & $3.71 \pm 5.24$ & $3.57 \pm 4.24$ & $4.21 \pm 4.92$ & $3.86 \pm 4.07$ & \multirow{3}{*}{0.23} \\
\hline & Active & $84.27 \pm 8.53$ & $1.07 \pm 6.63$ & $-0.53 \pm 8.98$ & $-1.53 \pm 7.28$ & $-2.80 \pm 7.08$ & \\
\hline & $p^{a}$ & 0.19 & 0.24 & 0.13 & 0.019* & $0.005 * *$ & \\
\hline \multirow{3}{*}{$\begin{array}{l}\text { SBP in subjects with } \\
\text { normal weight }(\mathrm{mmHg})\end{array}$} & Placebo & $132.25 \pm 11.62$ & $2.13 \pm 11.04$ & $1.00 \pm 9.91$ & $-2.13 \pm 10.39$ & $-3.42 \pm 12.30$ & \multirow{3}{*}{0.17} \\
\hline & Active & $131.48 \pm 12.64$ & $3.30 \pm 9.95$ & $3.36 \pm 12.32$ & $5.26 \pm 11.06$ & $-1.83 \pm 9.67$ & \\
\hline & $p^{a}$ & 0.83 & 0.70 & 0.48 & $0.023^{*}$ & 0.63 & \\
\hline \multirow{3}{*}{$\begin{array}{l}\text { DBP in subjects with } \\
\text { normal weight ( } \mathrm{mmHg} \text { ) }\end{array}$} & Placebo & $80.88 \pm 8.59$ & $1.79 \pm 5.39$ & $1.71 \pm 4.82$ & $0.79 \pm 4.09$ & $-0.83 \pm 4.72$ & \multirow{3}{*}{0.30} \\
\hline & Active & $80.30 \pm 8.41$ & $0.48 \pm 5.81$ & $1.86 \pm 7.50$ & $2.30 \pm 6.90$ & $-0.43 \pm 7.52$ & \\
\hline & $p^{a}$ & 0.82 & 0.43 & 0.93 & 0.36 & 0.83 & \\
\hline SBP in subjects with & Placebo & $132.00 \pm 8.84$ & $-0.38 \pm 9.91$ & $5.00 \pm 9.08$ & $3.58 \pm 12.84$ & $0.85 \pm 10.92$ & \multirow{3}{*}{$0.008 * *$} \\
\hline normal-high / class I & Active & $135.00 \pm 11.97$ & $4.29 \pm 12.63$ & $-0.21 \pm 16.25$ & $-4.36 \pm 13.70$ & $-2.79 \pm 15.56$ & \\
\hline obesity (mmHg) & $p^{a}$ & 0.47 & 0.30 & 0.32 & 0.14 & 0.49 & \\
\hline DBP in subjects with & Placebo & $81.31 \pm 7.55$ & $1.62 \pm 6.53$ & $3.46 \pm 4.98$ & $4.50 \pm 7.68$ & $2.77 \pm 6.55$ & \multirow{3}{*}{$0.009 * *$} \\
\hline normal-high obesity/ & Active & $84.57 \pm 6.45$ & $2.36 \pm 6.30$ & $0.07 \pm 7.79$ & $-1.64 \pm 7.28$ & $-0.64 \pm 7.62$ & \\
\hline class I obesity(mmHg) & $p^{a}$ & 0.24 & 0.77 & 0.19 & $0.047 *$ & 0.23 & \\
\hline
\end{tabular}

SBP, systolic blood pressure; DBP, diastolic blood pressure; $\Delta$ week 4 , change from baseline to week 4 ; $\Delta$ week 8 , change from baseline to week $8 ; \Delta$ week 12, change from baseline to week 12; $\Delta$ week 14, change from baseline to week 14 . Values are shown as the mean \pm standard deviation. Changes in subject values were analyzed using repeated measures ANOVA between the groups $\left(p^{\mathrm{b}}\right)$. Changes in subject values were analyzed using Student's $t$ test to compare the mean of the test food group and the placebo food group at each evaluation point $\left(p^{\mathrm{a}}\right)$. Statistically significant, ${ }^{*} p<0.05,{ }^{* *} p<0.01$. 
Effects of Plum Extract on VAS Scores: To confirm the effects of plum extract on fatigue, chillness, and bowel movements, we evaluated changes in VAS based on a questionnaire rating eight factors (Table 6). "Fatigue" was improved after ingestion of the active test food compared with the placebo food group (change from baseline to week 4: placebo, $-8.62 \pm 21.69 \mathrm{~mm}$; active, $5.05 \pm 16.81 \mathrm{~mm}, p=0.002$; change from baseline to week 12: placebo, $-1.64 \pm 19.33 \mathrm{~mm}$; active, $11.22 \pm 19.26 \mathrm{~mm}, p=0.007$; and change from baseline to week 14 : placebo, $0.51 \pm 21.96 \mathrm{~mm}$; active, $9.76 \pm 14.53 \mathrm{~mm}, p=0.021)$. Furthermore, ingestion of the active test food improved "defecation difficulty" at week 12 compared with the placebo food group (change from baseline to week 12: placebo, $-4.78 \pm 26.16 \mathrm{~mm}$; active, $-0.41 \pm 20.70 \mathrm{~mm}, p=0.045)$.

Table 6. Scores of VAS questionnaire

\begin{tabular}{|c|c|c|c|c|c|c|}
\hline & & Week 0 & $\Delta$ Week 4 & $\Delta$ Week 8 & $\Delta$ Week 12 & $\Delta$ Week 14 \\
\hline \multirow{3}{*}{ Fatigue (mm) } & Placebo & $72.11 \pm 21.31$ & $-8.62 \pm 21.69$ & $1.05 \pm 19.47$ & $-1.64 \pm 19.33$ & $0.51 \pm 21.96$ \\
\hline & Active & $57.54 \pm 23.45$ & $5.05 \pm 16.81$ & $6.47 \pm 17.71$ & $11.22 \pm 19.26$ & $9.76 \pm 14.53$ \\
\hline & $p$ & $0.007 * *$ & $0.002 * *$ & 0.09 & $0.007 * *$ & $0.021 *$ \\
\hline \multirow{3}{*}{$\begin{array}{l}\text { Stiffness of the neck and } \\
\text { shoulder }(\mathrm{mm})\end{array}$} & Placebo & $61.35 \pm 30.50$ & $1.97 \pm 17.73$ & $6.76 \pm 19.93$ & $4.14 \pm 22.68$ & $3.05 \pm 22.84$ \\
\hline & Active & $56.08 \pm 32.72$ & $1.81 \pm 22.80$ & $3.81 \pm 27.18$ & $-0.38 \pm 19.15$ & $2.03 \pm 22.04$ \\
\hline & $p$ & 0.56 & 0.97 & 0.46 & 0.35 & 0.70 \\
\hline \multirow{3}{*}{ Stiffness of waist (mm) } & Placebo & $72.43 \pm 26.68$ & $3.03 \pm 19.71$ & $2.46 \pm 23.88$ & $5.06 \pm 30.32$ & $3.24 \pm 26.64$ \\
\hline & Active & $75.95 \pm 23.55$ & $-3.68 \pm 16.95$ & $-7.06 \pm 23.80$ & $-6.78 \pm 22.70$ & $-4.14 \pm 18.89$ \\
\hline & $p$ & 0.88 & 0.64 & 0.21 & 0.23 & 0.48 \\
\hline \multirow{3}{*}{$\begin{array}{l}\text { Chillness in hands and feet } \\
(\mathrm{mm})\end{array}$} & Placebo & $84.51 \pm 22.34$ & $-2.16 \pm 20.11$ & $-21.78 \pm 29.49$ & $-16.64 \pm 35.56$ & $-12.62 \pm 33.02$ \\
\hline & Active & $81.84 \pm 19.92$ & $-4.51 \pm 18.53$ & $-19.86 \pm 25.25$ & $-15.84 \pm 28.67$ & $-12.89 \pm 20.26$ \\
\hline & $p$ & 0.20 & 0.59 & 0.92 & 1.00 & 0.69 \\
\hline \multirow{3}{*}{$\begin{array}{l}\text { Defecation regularity } \\
(\mathrm{mm})\end{array}$} & Placebo & $66.08 \pm 34.14$ & $2.57 \pm 18.06$ & $3.57 \pm 21.30$ & $5.31 \pm 18.00$ & $3.59 \pm 19.33$ \\
\hline & Active & $62.08 \pm 27.99$ & $-1.62 \pm 23.91$ & $1.17 \pm 21.39$ & $2.76 \pm 23.23$ & $0.73 \pm 26.98$ \\
\hline & $p$ & 0.42 & 0.60 & 0.87 & 0.60 & 0.96 \\
\hline \multirow{3}{*}{ Defecation difficulty (mm) } & Placebo & $78.38 \pm 22.84$ & $5.03 \pm 21.18$ & $-1.49 \pm 18.52$ & $-4.78 \pm 26.16$ & $-3.86 \pm 28.59$ \\
\hline & Active & $69.14 \pm 26.25$ & $2.11 \pm 16.34$ & $2.06 \pm 22.00$ & $-0.41 \pm 20.70$ & $-0.51 \pm 20.94$ \\
\hline & $p$ & 0.14 & 0.38 & 0.14 & $0.045^{*}$ & 0.46 \\
\hline \multirow{3}{*}{$\begin{array}{l}\text { Defecation satisfaction } \\
(\mathrm{mm})\end{array}$} & Placebo & $74.62 \pm 23.72$ & $-0.05 \pm 22.08$ & $0.84 \pm 21.35$ & $0.19 \pm 21.03$ & $0.89 \pm 26.73$ \\
\hline & Active & $73.19 \pm 26.42$ & $0.84 \pm 19.78$ & $-1.00 \pm 23.24$ & $-0.22 \pm 22.23$ & $-3.32 \pm 24.92$ \\
\hline & $p$ & 0.95 & 0.60 & 0.85 & 0.89 & 0.57 \\
\hline \multirow{3}{*}{ Fecal odor (mm) } & Placebo & $65.76 \pm 25.67$ & $7.16 \pm 22.90$ & $2.43 \pm 24.25$ & $1.86 \pm 25.11$ & $5.89 \pm 28.08$ \\
\hline & Active & $63.89 \pm 22.53$ & $2.68 \pm 17.02$ & $3.14 \pm 12.51$ & $3.16 \pm 15.37$ & $4.92 \pm 15.83$ \\
\hline & $p$ & 0.75 & 0.54 & 0.87 & 0.72 & 0.63 \\
\hline
\end{tabular}

$\Delta$ week 4, change from baseline to week 4; $\Delta$ week 8 , change from baseline to week $8 ; \Delta$ week 12, change from baseline to week 12. Values are shown as the mean \pm standard deviation. Changes in subject values were analyzed using Mann-Whitney's $U$ test to compare the mean of the test food group and the placebo food group at each evaluation point. *Statistically significant, $p<0.05$. 
Safety: We evaluated body composition, CBCs, and liver and renal function after ingestion of the test foods (Table 7). Although minimal changes were observed, these changes were within the normal range. Moreover, few subjects exhibited adverse effects. However, these subjects presented only mild symptoms and recovered within a few days. Therefore, the principal investigator judged that were no adverse events related to the ingestion of the test food. There were also no abnormal changes or severe adverse events observed in the physical, hematological, and biological examinations, and the medical interview in this trial and long-term intake of $3.0 \mathrm{~g}$ of plum extract was considered safe.

Table 7. Body composition, $\mathrm{CBC}$ parameters, liver, and renal function

\begin{tabular}{|c|c|c|c|c|c|}
\hline & & Week 0 & Week 4 & Week 8 & Week 12 \\
\hline \multirow{2}{*}{ BW (kg) } & Placebo & $56.29 \pm 11.27$ & $56.76 \pm 11.03$ & $56.35 \pm 10.94$ & $55.88 \pm 11.09$ \\
\hline & Active & $57.88 \pm 8.51$ & $58.04 \pm 8.47$ & $58.42 \pm 8.94$ & $58.24 \pm 9.01$ \\
\hline \multirow{2}{*}{ BFP (\%) } & Placebo & $27.16 \pm 6.36$ & $28.46 \pm 5.98$ & $28.12 \pm 7.26$ & $29.11 \pm 6.14$ \\
\hline & Active & $27.26 \pm 7.48$ & $27.56 \pm 7.27$ & $27.90 \pm 7.41$ & $27.91 \pm 7.11$ \\
\hline \multirow{2}{*}{ BMI $\left(\mathrm{kg} / \mathrm{m}^{2}\right)$} & Placebo & $22.40 \pm 3.14$ & $22.59 \pm 3.06$ & $22.55 \pm 3.15$ & $22.48 \pm 3.24$ \\
\hline & Active & $22.49 \pm 2.43$ & $22.49 \pm 2.33$ & $22.58 \pm 2.41$ & $22.53 \pm 2.42$ \\
\hline \multirow{2}{*}{$\begin{array}{l}\text { WBCs } \\
\left(\times 10^{3} / \mu \mathrm{l}\right)\end{array}$} & Placebo & $5.39 \pm 1.37$ & $5.39 \pm 1.17$ & $5.61 \pm 1.51$ & $5.56 \pm 1.26$ \\
\hline & Active & $5.62 \pm 2.03$ & $5.14 \pm 1.43$ & $4.97 \pm 1.40$ & $5.38 \pm 1.72$ \\
\hline \multirow{2}{*}{$\begin{array}{l}\text { RBCs } \\
\left(\times 10^{4} / \mu \mathrm{l}\right) \\
\end{array}$} & Placebo & $467.08 \pm 56.25$ & $472.18 \pm 53.31$ & $475.28 \pm 52.80$ & $478.97 \pm 51.92$ \\
\hline & Active & $463.08 \pm 44.08$ & $461.62 \pm 49.07$ & $470.25 \pm 49.08$ & $471.41 \pm 51.75$ \\
\hline \multirow{2}{*}{$\mathrm{Hb}(\mathrm{g} / \mathrm{dl})$} & Placebo & $13.60 \pm 1.18$ & $13.81 \pm 1.24$ & $13.88 \pm 1.34$ & $13.80 \pm 1.29$ \\
\hline & Active & $13.67 \pm 1.49$ & $13.69 \pm 1.69$ & $13.85 \pm 1.67$ & $13.91 \pm 1.71$ \\
\hline \multirow{2}{*}{$\mathrm{Ht}(\%)$} & Placebo & $41.40 \pm 3.55$ & $42.17 \pm 3.61$ & $42.48 \pm 3.80$ & $42.53 \pm 3.45$ \\
\hline & Active & $41.57 \pm 3.90$ & $41.82 \pm 4.72$ & $42.55 \pm 4.36$ & $42.65 \pm 4.40$ \\
\hline \multirow{2}{*}{ Plt $\left(\times 10^{4} / \mu \mathrm{l}\right)$} & Placebo & $23.27 \pm 4.37$ & $23.67 \pm 4.92$ & $25.05 \pm 5.32$ & $25.78 \pm 5.05$ \\
\hline & Active & $23.74 \pm 6.03$ & $23.30 \pm 5.84$ & $23.41 \pm 6.11$ & $23.88 \pm 5.75$ \\
\hline \multirow{2}{*}{ AST (U/l) } & Placebo & $22.33 \pm 5.63$ & $23.45 \pm 7.59$ & $22.80 \pm 5.98$ & $22.30 \pm 6.05$ \\
\hline & Active & $22.60 \pm 5.72$ & $22.15 \pm 4.20$ & $22.25 \pm 5.02$ & $23.03 \pm 7.11$ \\
\hline \multirow{2}{*}{$\operatorname{ALT}(\mathrm{U} / \mathrm{l})$} & Placebo & $20.31 \pm 12.12$ & $20.90 \pm 12.93$ & $20.68 \pm 12.54$ & $19.65 \pm 9.75$ \\
\hline & Active & $21.13 \pm 10.30$ & $20.18 \pm 7.37$ & $20.83 \pm 8.79$ & $20.35 \pm 9.42$ \\
\hline \multirow{2}{*}{$\gamma$-GTP (U/l) } & Placebo & $30.00 \pm 28.10$ & $31.55 \pm 34.31$ & $30.95 \pm 32.89$ & $30.32 \pm 27.07$ \\
\hline & Active & $28.43 \pm 20.25$ & $28.49 \pm 19.74$ & $27.78 \pm 20.58$ & $28.89 \pm 20.51$ \\
\hline \multirow{2}{*}{ ALP (U/l) } & Placebo & $213.08 \pm 42.70$ & $222.43 \pm 56.68$ & $227.28 \pm 66.38$ & $228.03 \pm 41.16$ \\
\hline & Active & $211.15 \pm 57.76$ & $209.74 \pm 56.88$ & $206.92 \pm 53.15$ & $209.70 \pm 52.61$ \\
\hline \multirow{2}{*}{ LDH (U/l) } & Placebo & $200.28 \pm 32.02$ & $198.58 \pm 37.09$ & $191.20 \pm 30.40$ & $199.92 \pm 34.55$ \\
\hline & Active & $200.53 \pm 34.53$ & $193.82 \pm 30.79$ & $189.31 \pm 32.15$ & $197.35 \pm 34.74$ \\
\hline \multirow{2}{*}{ BUN (mg/dl) } & Placebo & $14.13 \pm 3.28$ & $14.31 \pm 3.75$ & $14.43 \pm 4.15$ & $13.75 \pm 3.40$ \\
\hline & Active & $14.17 \pm 3.36$ & $14.32 \pm 3.19$ & $14.47 \pm 3.29$ & $14.11 \pm 2.88$ \\
\hline \multirow{2}{*}{ CRE (mg/dl) } & Placebo & $0.77 \pm 0.12$ & $0.75 \pm 0.11$ & $0.76 \pm 0.13$ & $0.74 \pm 0.11$ \\
\hline & Active & $0.77 \pm 0.14$ & $0.76 \pm 0.13$ & $0.77 \pm 0.14$ & $0.76 \pm 0.12$ \\
\hline \multirow{2}{*}{$\mathrm{UA}(\mathrm{mg} / \mathrm{dl})$} & Placebo & $5.34 \pm 1.23$ & $5.21 \pm 1.12$ & $5.12 \pm 1.13$ & $4.98 \pm 1.11$ \\
\hline & Active & $5.05 \pm 1.34$ & $5.04 \pm 1.29$ & $4.98 \pm 1.39$ & $4.90 \pm 1.16$ \\
\hline
\end{tabular}

Values are shown as the mean \pm standard deviation. 


\section{DISCUSSION}

This clinical trial showed that plum extract-processed food displayed more beneficial effects on BP in subjects with $\mathrm{SBP} \geq 130$ and $<160 \mathrm{mmHg}$. There were no significant differences between the active test food and placebo food groups regarding changes in the level of SBP and DBP. However, in subjects with grade I hypertension or normal to high obesity/class I obesity, DBP significantly decreased in the active test food group compared with the placebo food group at week 12 , results suggesting improvement.

The evaluation of DBP was influenced by endothelial function, such as vascular stiffness. It was reported that citric acid and mumefural improved blood flow via inhibition of platelet aggregation and promotion of erythrocyte deformability [9]. In addition, previous research has been revealed that the active center of mumefural was the residue derived from citric acid [15]. Endothelial function demonstrated a change in morphology, gene, and protein expression of nitric oxide and adhesion molecules and signal transduction of calcium and potassium due to mechanical actions such as shear stress and extension by blood flow [15]. These findings suggested that plum extract inhibited the increase of DBP by improving blood flow via citric acid and mumefural contained in the plum extract. However, the VAS question relating to chillness (improvement of blood flow) was not changed by ingestion of active test food. The biological mechanism of these results needs to be elucidated to fully understand the effects of plum extract. Additionally, DBP was significantly decreased in the active test food group at 2 weeks after the end of test food ingestion. This suggests that the effect of the plum extract persisted after the intake period.

Moreover, as an exploratory subgroup analysis, DBP significantly decreased at week 12 and time-group interaction of change value of DBP was significant following ingestion of the active test food in subject with normal to high obesity or class I obesity. Furthermore, SBP tended to decrease at week 12, and the time-group interaction of change value of SBP was significant in the same subject group. Previous research reported a correlation between obesity and hypertension [16]. Moreover, cytokines and adipokines secreted from increased adipose tissue induced endothelial dysfunction and atherosclerosis [17]. It is suspected that endothelial function of subjects with normal to high obesity/class I obesity is impaired compared with normal weight subjects. These findings suggest that plum extract was more effective in subjects with normal to high obesity/class I obesity.

The VAS questionnaire indicated that fatigue was improved by ingestion of active test food at weeks 4 and 12 and at week 2 after the intake period. Active test food contained $1.119 \mathrm{~g}$ of citric acid. A previous clinical study reported that ingestion of drink containing lemon citric acid $(2,700$ 
$\mathrm{mg}$ ) attenuated the fatigue feeling in VAS for people frequently feeling fatigue by continuing intake for 28-week [18]. Other clinical study reported that the continued intake of $2,700 \mathrm{mg} / \mathrm{day}$ of citric acid for 8 weeks reduced physiological stress and attenuated physical fatigue [11]. These findings suggest that the citric acid contained in plum extract may improve feelings of fatigue. However, our clinical trial only used an objective evaluation to assess fatigue. Moreover, initial values were significantly different among the two groups. Further research is required to determine the effects of plum extract on fatigue such as evaluating stress markers. Furthermore, the VAS question relating to "defecation difficulty" showed improvement following the ingestion of active test food at week 12. A previous study suggested that consumption of carbohydrate-free plum juice for 11 weeks had the potential to modify fecal microbial ecology in an obese animal model [19]. Further clinical trials into constipation are required to assess the effects of plum extract on intestinal flora.

In our clinical study, no abnormal changes or severe adverse events were observed in the physical and blood examinations or reported in the medical interviews during the trial. These results confirm the safety of 12 -week ingestion of $3.0 \mathrm{~g}$ of plum extract.

The results of this study reveal that plum extract improved DBP in subjects with grade I hypertension or normal to high obesity/class I obesity. Furthermore, plum extract had positive effects on fatigue and bowel movements.

\section{CONCLUSION}

The present study was a 12-week randomized, double-blinded, placebo-controlled parallel group comparison study to determine the effects of consuming plum extract among subjects with normal high blood pressure/grade I hypertension. It was revealed that plum extract improved DBP in subjects with grade I hypertension or normal to high obesity/class I obesity. Moreover, plum extract had positive effects on fatigue and bowel movements. Our results confirmed the safety of 12 -week ingestion of $3.0 \mathrm{~g}$ of plum extract. Although the biological mechanism of these results needs to be elucidated to fully understand the effects of plum extract, plum extract will be used as a new functional food for mild hypertension in the future.

List of Abbreviations: ALT, alanine aminotransferase; ALP, alkaline phosphatase; ANOVA, analysis of variance; AST, aspartate aminotransferase; BP, blood pressure; BUN, blood urea nitrogen; BFP, body fat percentage; BMI, body mass index; BW, body weight; $\mathrm{CBCs}$, complete blood counts; CRE, creatinine; DBP, diastolic blood pressure; $\gamma$-GTP, gamma glutamyl transpeptidase; Ht, hematocrit; Hb, hemoglobin; LDH, lactate dehydrogenase; Plt, platelet counts; 
RBCs, red blood cells; SBP, systolic blood pressure; UA, uric acid; VAS, visual analog scale; WBCs, white blood cells.

Competing Interests: This study was funded by NAKANO BC Co., Ltd. The conflicts of interest were judged and approved by the Hokkaido Information University ethics review committee.

Authors' Contributions: JN, MN, HK, AK, and NG designed the research. HK, AK, and NG provided test food. $\mathrm{JN}$ conducted the research. MN performed statistical analyses. $\mathrm{MN}$ and $\mathrm{JN}$ wrote the manuscript. JN had primary responsibility for the final content. All authors read and approved the final version of the manuscript.

Acknowledgments and Funding: We thank the members of Hokkaido Information University, Center of Health Information Science (Anzai Y., Fukuda Y., Ito M., Kamo S., Koyama S., Miyao A., Obata N., Ohkubo Y., Ohshima M., Saito T., Saito Y, Sasaki M., Sato K., Shima N., Tanaka A., Teramoto M., and Tsunemine S.) for their technical assistance with the clinical trial. This study was conducted with research funds under contract with Nakano BC, Co. Ltd., Wakayama, Japan, and supported in part by Grants-in-Aid for Regional R\&D Proposal-Based Program from Northern Advancement Center for Science \& Technology of Hokkaido Japan.

\section{REFERENCES:}

1. Shimamoto K, Ando K, Fujita T, Hasebe N, Higaki J, Horiuchi M, et al., and Japanese Society of Hypertension Committee for Guidelines for the Management Of H: The Japanese Society of Hypertension Guidelines for the Management of Hypertension (JSH 2014). Hypertens Res 2014, 37:253-390.

2. Iimura O: Insulin resistance and hypertension in Japanese. Hypertens Res 1996, 19 Suppl $1: \mathrm{S} 1-8$.

3. Kushiro T, Mizuno K, Nakaya N, Ohashi Y, Teramoto T, Yokoyama S, Kakinoki S, Nakamura H, Group MS: Blood pressure control status and effects of pravastatin on cardiovascular events occurrence in patients with dyslipidaemia. J Hum Hyperten 2012, 26:388-395.

4. Chei CL, Yamagishi K, Tanigawa T, Kitamura A, Imano H, Kiyama M, Sato S, Iso H: Metabolic Syndrome and the Risk of Ischemic Heart Disease and Stroke among MiddleAged Japanese. Hypertens Res 2008, 31:1887-1894. 
5. Skoog I, Lernfelt B, Landahl S, Palmertz B, Andreasson LA, Nilsson L, Persson G, Oden A, Svanborg A: 15-year longitudinal study of blood pressure and dementia. Lancet 1996, 347:1141-1145.

6. Miura K, Nagai M, Ohkubo T: Epidemiology of hypertension in Japan: where are we now? Circ J 2013, 77:2226-2231.

7. Munn MS, Sibley S, Brundage R, Ismail B, Earthman CP: Angiotensin-converting enzyme inhibitory effects of dairy- and soy-derived peptides in pre-hypertensive overweight men and women. Functional Foods in Health and Disease 2013, 3:37-47.

8. Herrlinger K, Ceddia M, Chirouzes D, Katz A, Capodice J: A randomized double blind study of a green and black tea agent, AssuriTEA ${ }^{\circledR}$, in healthy male subjects. Functional Foods in Health and Disease 2015, 5:350-364.

9. Kubo M, Yamazaki M, Matsuda H, Gato N, Kotani T: Effect of Fruit-Juice Concentrate of Japanese Apricot (Prunus mume SEIB. et ZUCC.) on Improving Blood Fluidity (in Japanese). Natural Medicines 2005, 59:22-27.

10. Chuda Y, Ono H, Ohnishi-Kameyama M, Matsumoto K, Nagata T, Kikuchi Y: Mumefural, citric acid derivative improving blood fluidity from fruit-juice concentrate of Japanese apricot (Prunus mume Sieb. et Zucc). J Agric Food Chem 1999, 47:828-831.

11. Sugino T, Aoyagi S, Shirai T, Kajimoto Y, Kajimoto O. Effects of Citric Acid and 1Carnitine on Physical Fatigue. J Clin Biochem Nutr 2007, 41:224-230.

12. Monchi M: Citrate pathophysiology and metabolism. Transfus Apher Sci 2017, 56:2830.

13. Truss NJ, Armstrong PC, Liverani E, Vojnovic I, Warner TD: Heparin but not citrate anticoagulation of blood preserves platelet function for prolonged periods. J Thromb Haemost 2009, 7:1897-1905.

14. Gato N, Ono H, Kikuchi Y, Chuda Y: Mumefural-related compounds in fruit-juice concentrate of Japanese apricot and their ameliorating effect on blood fluidity through capillaries (in Japanese). Hemorheology and related research 2000, 3:81-88.

15. Mitsumata M: Endothelial Cells Reacting to the Blood Flow (in Japanese). J Jpn Coll Angiol 2003, 43:733-743.

16. Must A Mckeown NM: The Disease Burden Associated with Overweight and Obesity, in Endotext. South Dartmouth, MA; 2000.

17. Lau DC, Dhillon B, Yan H, Szmitko PE, Verma S: Adipokines: molecular links between obesity and atheroslcerosis. Am J Physiol Heart Circ Physiol 2005, 288:H2031-2041. 
18. Kaiimoto O, Mieda H, Hiramatsu M, Sakaida K, Yasuda T, Sugino T, Kajimoto Y: The Internet Investigation about the Attenuation of Fatigue Feeling by Thking a Drink Containing Lemon Citric Acid (in japanese). Jpn Pharmacol Ther 2007, 35:821-828.

19. Noratto GD, Garcia-Mazcorro JF, Markel M, Martino HS, Minamoto Y, Steiner JM, Byrne D, Suchodolski JS, and Mertens-Talcott SU: Carbohydrate-Free Peach (Prunus persica) and Plum (Prunus salicina) [corrected] Juice Affects Fecal Microbial Ecology in an Obese Animal Model. PLoS One 2014, 9:e101723. 